Gut, 1960, 1, 357.

New Methods for Diagnosis and Research

\title{
PERCUTANEOUS TRANSHEPATIC CHOLANGIOGRAPHY
}

\author{
BY \\ MICHAEL ATKINSON, MARGARET G. HAPPEY, and FRANCIS G. SMIDDY \\ From the Departments of Medicine and Surgery, the University of Leeds, and the Department of Radiology, \\ St. James's Hospital, Leeds
}

This is an evaluation of percutaneous transhepatic cholangiography, a technique of over eight years' standing, previously considered by many authorities as both unrewarding and dangerous. The value and risks of the procedure have been examined in 20 patients with obstructive jaundice of uncertain origin and in one further patient with a poșt-cholecystectomy syndrome. The presence and the nature of extrahepatic obstructive lesions was correctly diagnosed in 10 of 11 patients shown to have this cause for jaundice. The failure to obtain cholangiograms in the remaining 10 patients was correctly correlated with the presence of intrahepatic obstructive disease due to hepatitis or primary biliary cirrhosis. The risks of percutaneous cholangiography seem over-rated, biliary peritonitis occurring in under $5 \%$ of patients submitted to the procedure.

Cholangiography by means of intravenously administered agents is rarely successful in the presence of deep jaundice, and laparotomy, with or without operative cholangiography, is usually required to demonstrate the site and nature of obstructive lesions in the bile passages. In recent years attempts have been made to opacify the biliary tree by direct percutaneous injection of contrast medium. This was achieved by Royer and Solari (1947) who injected dye into the gall-bladder under direct vision at peritoneoscopy. Although they considered the risk of leakage of bile to be small, fear of this complication led others to use the transhepatic route. Kapandji (1950) punctured the gall-bladder, previously opacified by giving pheniodol, under fluoroscopic control using the percutaneous transhepatic approach. Cholangiography by means of percutaneous puncture of the intrahepatic biliary tree had in fact been described by Huard and Do-Xuan-Hop as long ago as 1937. They punctured the intrahepatic biliary tree in three patients with extrahepatic biliary obstruction and injected "lipiodol" into two of these, thus demonstrating dilatation of the bile passages. In 1952, Carter and Saypol's paper aroused general interest in this technique and since then a number of reports of percutaneous transhepatic cholangiography have appeared (Table II), chiefly in the South American and French literature.

Kidd (1956) enumerated four indications for the procedure: first, to investigate the cause of biliary symptoms after cholecystectomy, secondly to diagnose the presence and site of a carcinoma of the biliary system, thirdly to demonstrate the site of calculous disease, and lastly directly to measure biliary pressure. Remolar, Katz, Rybak, and Pellizari (1956) considered the technique to be of value in the diagnosis of jaundice of doubtful aetiology, to differentiate calculus from carcinomatous biliary obstruction, and to investigate jaundice following cholecystectomy. However, percutaneous transhepatic cholangiography has not as yet gained general acceptance, principally because many clinicians fear the risk of causing biliary peritonitis.

We considered that the results previously reported were sufficiently encouraging to warrant a further reappraisal of the procedure, and this report deals with 21 patients in whom percutaneous transhepatic cholangiography has been performed.

\section{TECHNIQUE}

The procedure can conveniently be carried out in the $x$-ray department under local anaesthesia with $2 \%$ lignocaine B.P. In children or adults who are uncooperative, general anaesthesia with tracheal intubation and controlled respiration is to be preferred.

With the patient lying supine, a short bevelled needle, $12 \mathrm{~cm}$. in length and of $1 \mathrm{~mm}$. bore with a $20 \mathrm{ml}$. syringe containing saline attached, is introduced through the abdominal parietes at a point $2-4 \mathrm{~cm}$. below and to the right of the xiphisternum. The needle is inclined in a slightly cephalad direction. An increased resistance can be felt when the needle enters the liver and, at this point if general anaesthesia is being used, respiration is controlled, or if under local anaesthesia, the patient is asked to breathe shallowly. The needle is then cleared 
by injecting a few millilitres of saline and slowly advanced 6-8 cm., exerting constant suction with the syringe. It is then cleared again by injecting saline and slowly withdrawn, again applying suction. Entry into a bile passage is indicated by the aspiration of bile or white bile (mucus) into the syringe. To facilitate the detection of bile the syringe should contain clear saline and if penetration of a blood vessel causes this to become bloodstained, it should be replaced. Good lighting is essential and the procedure is best carried out in daylight to enable the brown coloration of the bile to be recognized. On one occasion deeply bile-stained ascitic fluid was aspirated and was mistaken for true bile. If no bile passage is penetrated this procedure is repeated, inclining the needle towards the right side, and if still unsuccessful a third attempt is made, this time inclining the needle towards the left. In one patient, after failure to penetrate a bile duct by this approach, puncture in the midaxillary line was successful.

If a duct is entered aspiration is continued until no further bile can be obtained and the m-terial sent for microscopy and culture. At this point it is essential that breathing be controlled since it is extremely easy accidentally to withdraw the needle from the duct or alternatively to tear the liver capsule. Then $10-20 \mathrm{ml}$. of $85 \%$ "hypaque" (Winthrop) is injected under fluoroscopic control if this is available. Films are taken as the contrast medium spreads throughout the biliary tree and filling of the lower part of the common duct may be facilitated by tilting the patient feet downwards. At this juncture barium may be given by mouth to outline the duodenum (Remolar et al., 1956) thus obtaining an indication of

\section{HAPPEY, AND FRANCIS G. SMIDDY}

the extent of any suprapapillary blockage of the duct. However, if barium is given great care is necessary to avoid obscuring detail of the lower end of the common duct.

The initial high density of contrast medium in the common duct provides a clear-cut picture of the biliary tree but may obscure filling defects. For this reason further films are taken over the next four to eight hours as the density of the contrast medium is diminishing.

Patients are placed on a hourly pulse chart for 24 hours after this procedure and the abdomen is carefully examined should the pulse rate rise or abdominal pain occur.

\section{RESULTS}

Of the 21 patients investigated by this technique, all except one were suffering from jaundice of the obstructive type. The remaining patient complained of attacks of severe upper abdominal pain following cholecystectomy. The final diagnosis in each patient is shown in Table I. In 11 patients a biliary radical was entered and contrast medium injected into the biliary tree; in the remaining 10 patients a bile duct was not encountered.

In each of the 11 patients in whom cholangiograms were obtained, an extrahepatic obstructive lesion was demonstrated to be the cause of the jaundice. The common duct was considerably dilated, varying between 1.2 and $2.5 \mathrm{~cm}$. in width, and the intrahepatic biliary tree was also distended.

TABLE I

CLINICAL SUMMARY

\begin{tabular}{|c|c|c|c|c|c|c|}
\hline $\begin{array}{l}\text { Case } \\
\text { No. }\end{array}$ & Sex & Age & $\begin{array}{l}\text { Duration } \\
\text { of Jaundice } \\
\text { in Months }\end{array}$ & $\begin{array}{l}\text { Cholangiographic } \\
\text { Findings }\end{array}$ & $\begin{array}{l}\text { Cholangiographic } \\
\text { Diagnosis }\end{array}$ & Operative Findings \\
\hline 1 & $\mathbf{F}$ & 77 & 24 & Filling defects in common & Stones & Stones in common duct \\
\hline 2 & $\mathbf{F}$ & 62 & 3 & $\begin{array}{l}\text { Dilated common duct with } \\
\text { no filling defects in } 10 \mathrm{~min} .\end{array}$ & Carcinoma of pancreas & Stones in common duct \\
\hline 3 & $\mathbf{F}$ & 55 & $1 \frac{1}{2}$ & Single filling defect in & Stones & Stones in common duct \\
\hline 4 & $\mathbf{M}$ & 80 & 1 & Multiple filling defects in & Stones & Stones in common duct \\
\hline 5 & $\mathbf{F}$ & 65 & 2 & $\begin{array}{l}\text { Dilatation of ducts of right } \\
\text { lobe with no filling of re- }\end{array}$ & Carcinoma at porta hepatis & $\begin{array}{l}\text { Carcinoma of bile duct at } \\
\text { porta hepatis }\end{array}$ \\
\hline 6 & $\mathbf{M}$ & 80 & 3 & $\begin{array}{l}\text { Dilatation of whole biliary } \\
\text { tree }\end{array}$ & Carcinoma of pancreas & $\underset{\text { necropsy }}{\text { Carcinoma of pancreas at }}$ \\
\hline $\begin{array}{r}7 \\
8 \\
9 \\
10 \\
11\end{array}$ & $\begin{array}{l}\mathbf{F} \\
\mathbf{F} \\
\mathbf{F} \\
\mathbf{M}\end{array}$ & $\begin{array}{l}35 \\
60 \\
62 \\
65 \\
62\end{array}$ & $\begin{array}{l}2 \\
1 \frac{1}{2} \\
2 \\
1 \\
11\end{array}$ & ", & ", & ", \\
\hline 12 & $\begin{array}{l}\mathbf{M} \\
\mathbf{F}\end{array}$ & $\begin{array}{l}50 \\
35\end{array}$ & $5^{12}$ & $\begin{array}{l}\text { Negätive } \\
\text {, }\end{array}$ & $\ddot{z}$ & $\begin{array}{c}\text { Cholangiolytic hepatitis } \\
\#\end{array}$ \\
\hline $\begin{array}{l}14 \\
15\end{array}$ & $\begin{array}{l}\mathbf{M} \\
\mathbf{M}\end{array}$ & $\begin{array}{l}58 \\
22\end{array}$ & 3 & $"$ & 二 & Neonatal hepatitis \\
\hline $\begin{array}{l}16 \\
17\end{array}$ & $\mathbf{M}$ & $\begin{array}{l}45 \\
52\end{array}$ & $\begin{array}{r}4 \\
12\end{array}$ & $"$ & 二 & $\begin{array}{c}\text { Primary biliary cirrhosis } \\
\text { " }\end{array}$ \\
\hline $\begin{array}{l}18 \\
19\end{array}$ & $\mathbf{F}$ & $\begin{array}{l}36 \\
57\end{array}$ & $\begin{array}{l}24 \\
60\end{array}$ & $"$ & 二 & " \\
\hline 20 & $\mathbf{F}$ & 55 & $1 \frac{1}{2}$ & $"$ & - & $\begin{array}{l}\text { Massive infiltration of liver by } \\
\text { malignant melanoma } \\
\text { necropsy }\end{array}$ \\
\hline 21 & $\mathbf{F}$ & 53 & - & " & - & $\begin{array}{l}\text { No operation, eventual diag } \\
\text { nosis post-cholecystectomy } \\
\text { syndrome }\end{array}$ \\
\hline
\end{tabular}


In the majority of patients the contrast medium diffused throughout the biliary tree filling the gallbladder and cystic duct. Emptying into the duodenum was delayed and the dye could sometimes be detected in the biliary tree next day. In several patients the obstruction appeared to be complete and in these the dye was presumably reabsorbed into the blood stream.

The nature of the obstructive lesion was diagnosed correctly in 10 of the 11 patients in whom cholangiography was successful (Table I).

Stones IN THE Common Duct.-These were identified as filling defects in the common duct shadow in three patients. In a fourth patient common duct stones were obscured by the initial density of the contrast medium and no subsequent films were obtained, the diagnosis being incorrectly presumed to be carcinoma of the pancreas. After this experience it was decided to take serial films at intervals following the injection and these on two occasions revealed filling defects due to calculi which had not been apparent in the initial films (Figs. 2, 3, and 4).

Carcinoma of Pancreas.-This was diagnosed correctly in each of the seven patients in whom carcinoma was subsequently found at laparotomy. No characteristic deformity of the lower end of the common duct could be identified. The degree of dilatation of the biliary passages might be expected to be greater in patients with neoplastic obstruction than in those with common duct stones. However, no such difference was detectable in this series, and it appears that the diameter of the ducts is of little diagnostic value in deciding the cause of the obstruction in the individual patient. The diagnosis of carcinoma of the head of the pancreas has been made by demonstrating rapid filling of the biliary tree and common duct without emptying into the duodenum. Serial films are essential to exclude an intraluminal cause of obstruction.

Carcinoma of Bile Ducts.-Carcinoma of the bile ducts at the porta hepatis was present in one patient in whom the correct diagnosis was made by cholangiography (Fig. 6).

In the 10 remaining patients the examination was abandoned after failure to penetrate a bile passage. Because of continuing jaundice of uncertain aetiology, nine of these patients underwent laparotomy and liver biopsy. In each the site of obstruction proved to be intrahepatic (Table I); the final diagnosis was primary biliary cirrhosis in four, cholangiolytic hepatitis in three, neonatal hepatitis in one, and massive infiltration of the liver with melanomatous deposits in one. The tenth patient, who suffered from attacks of severe upper abdominal pain following cholecystectomy and was not jaundiced, showed normal histological appearances on needle liver biopsy and has not been investigated further.

\section{Illustrative CASEs}

CASE 3.-M.B. was a woman aged 55.

History.-Jaundice, intermittent pain in the right loin, and malaise began six weeks before admission to hospital. She had previously had an attack of jaundice at 15 years of age. Physical examination revealed deep jaundice and a liver palpable two fingerbreadths below the right costal margin. Biochemical tests indicated that the jaundice was obstructive in nature, the alkaline phosphatase being 37 units and serum bilirubin $6.2 \mathrm{mg}$. $\%$. A straight radiograph of the abdomen showed a single calcified opacity overlying the right renal shadow (Fig. 1).

Transhepatic Cholangiography.-Immediate biliary puncture was obtained and bile aspirated. Injection of $85 \%$ "hypaque" demonstrated a dilated common duct, the lower end of which appeared normal. At 10 minutes the opacity seen in the straight film was obscured (Fig. 2) but in the 20- and 30-minute films it was revealed as a

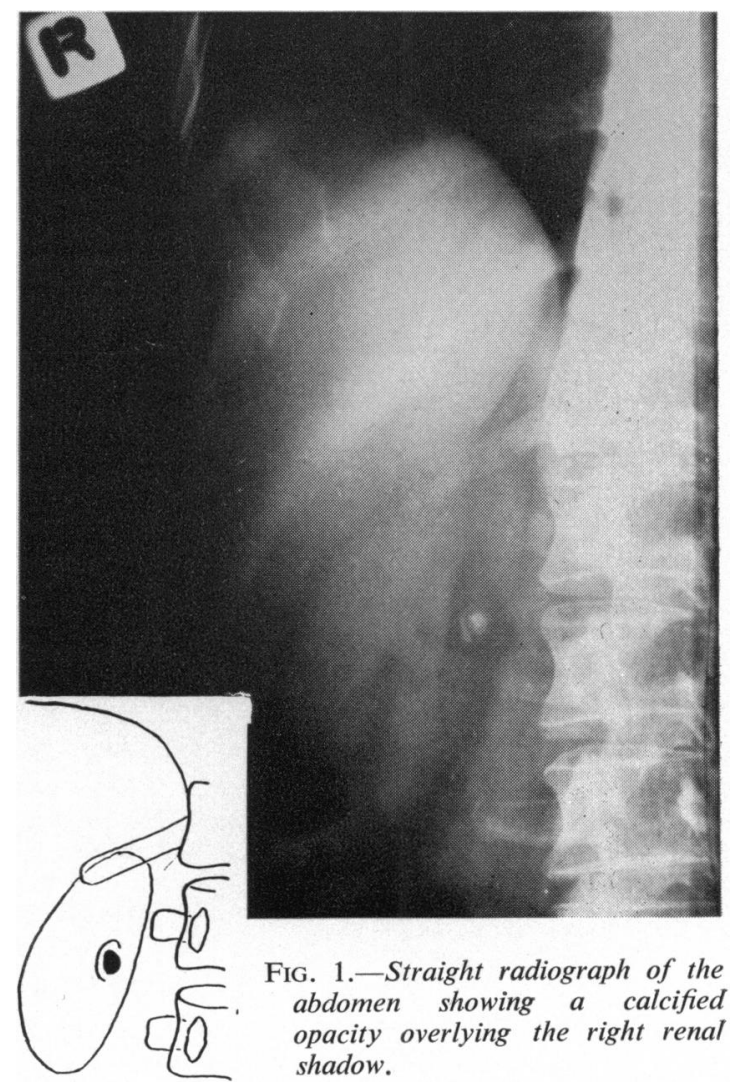




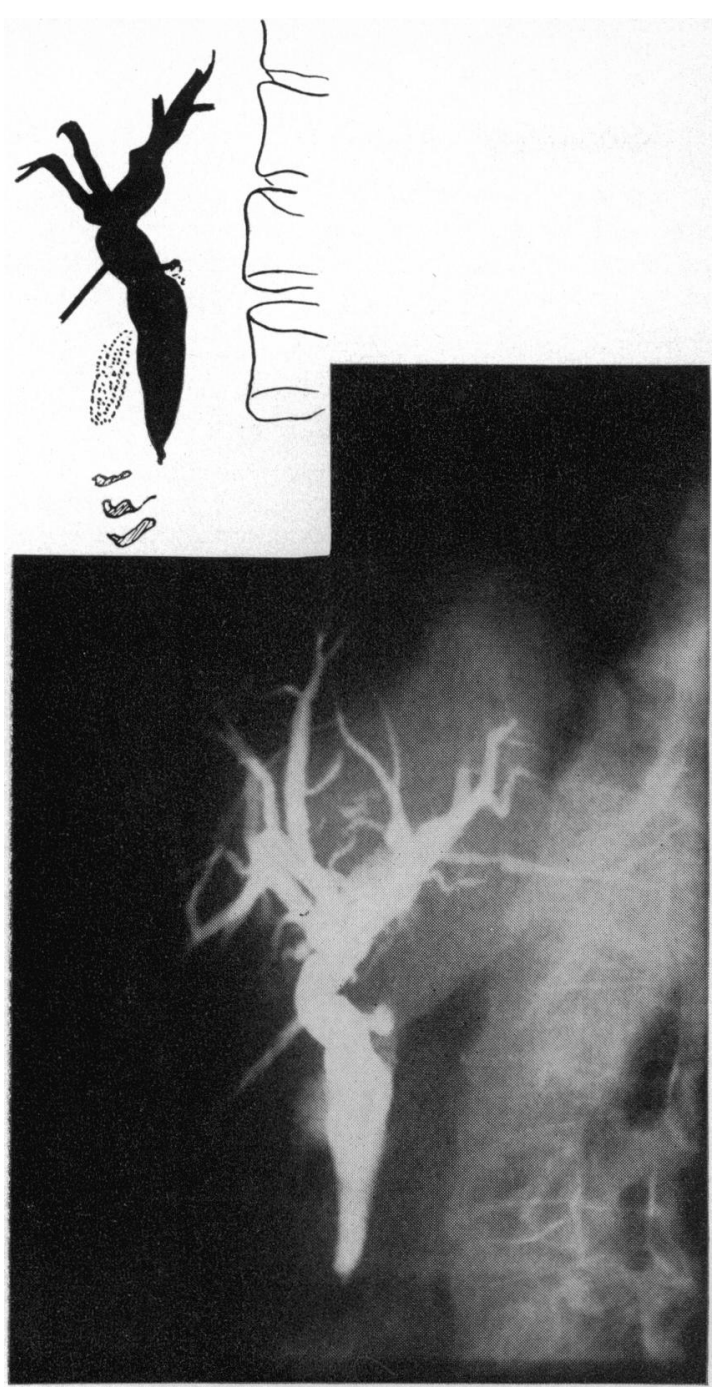

FIG. 2

FIG. 2.-Film taken 10 minutes after the injection of "hypaque" showing dilatation of the biliary tree, with medium passing into the duodenum.

FIG. 3.-Twenty-minute film showing the gall-bladder beginning to fill. A filling defect is now apparent in the common duct.

FIG. 4.-Thirty-minute film showing with greater clarity the filling defect in the common bile duct. The appearance of the gall-bladder in this film suggests cholelithiasis but no gall stones were present in the gall-bladder.
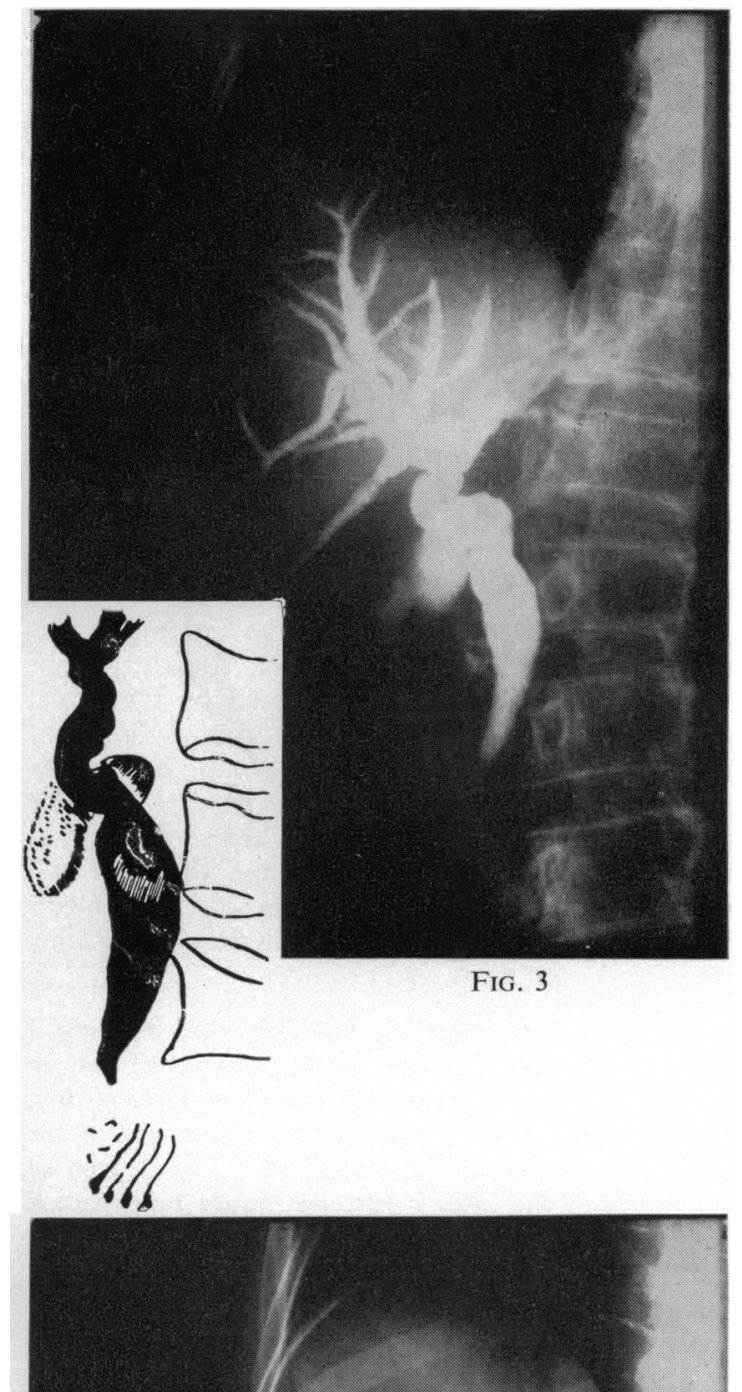$$
\text { 2. }
$$
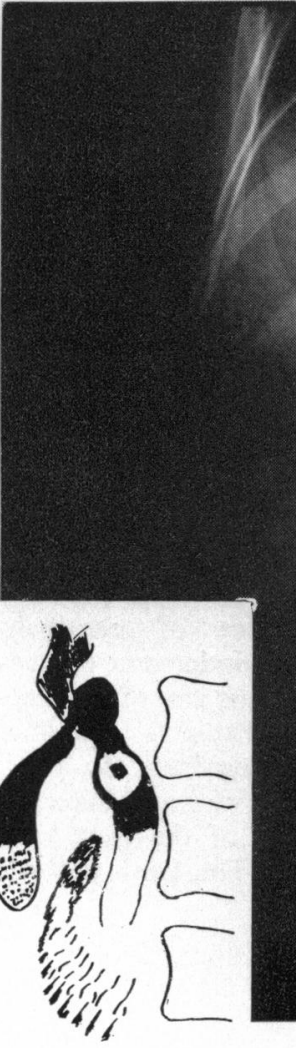

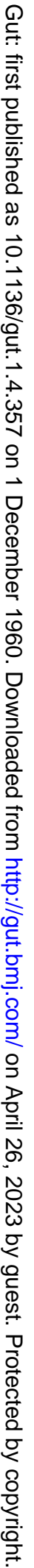




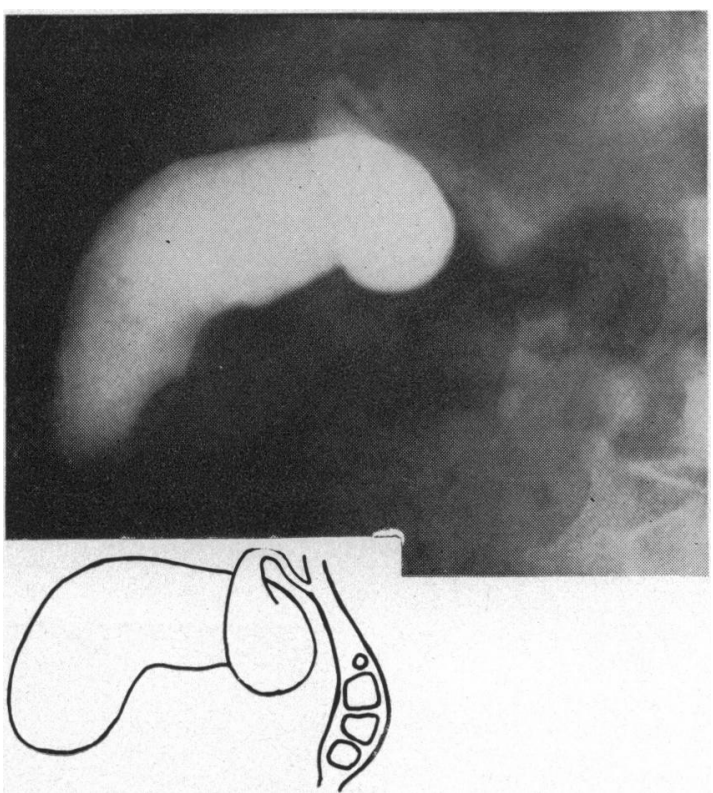

FIG. 5.-Radiograph showing a large gall-bladder and a dilated common bile duct in which several filling defects can be identified, indicating a column of faceted stones.

negative filling defect in the common bile duct (Figs. 3 and 4). The presence of contrast medium in the duodenal loop demonstrated that the obstruction was incomplete. The diagnosis was confirmed by subsequent laparatomy when a single cholesterol stone was removed from the common bile duct.

\section{CASE 4.-R.J. was a man aged 80.}

History.-After being jaundiced and febrile for several days he was admitted to hospital in a semi-comatose condition. He had had an episode of fever and jaundice four months previously which had subsided after several weeks' conservative treatment.

Examination revealed moderate jaundice, foetor hepaticus, and a flapping tremor. The liver was enlarged to two fingerbreadths below the costal margin.

A diagnosis of cholangitis was made and treatment with broad-spectrum antibiotics and dietary protein restriction led to a striking response and improvement in the jaundice.

Transhepatic Cholangiography.-This, performed six weeks after admission, revealed a dilated biliary tree. Although not apparent on the initial film, a column of faceted gall stones was visible in the common duct in the 60 min. film (Fig. 5).

CASE 5.-N.H. was a woman aged 65.

History.-Ten days after an influenzal-like illness jaundice developed. On admission to hospital six weeks later she was deeply jaundiced with moderate ascites. Liver function tests did not help to decide whether the jaundice was parenchymatous or obstructive in type, the serum bilirubin being $12 \mathrm{mg} . \%$ and the alkaline phosphatase 32 units. Liver biopsy indicated biliary obstruction showing bile thrombi, bile duct proliferation, and bile lakes.

Transhepatic Cholangiography.-This (Fig. 8) was performed after eight weeks of jaundice; a bile passage was entered with ease but only "white bile" was aspirated. After $7 \mathrm{ml}$. of bile had been removed $10 \mathrm{ml}$. $85 \%$ "hypaque" was injected against increasing resistance. Subsequent films showed dilatation of the right hepatic ducts only and extravasation of the contrast medium into the hepatic substance. A tentative diagnosis of carcinoma of the porta hepatis was made and subsequent laparotomy revealed a mass of malignant tissue obstructing the biliary tree at the junction of the right and left hepatic ducts and compressing the portal vein.

CASE 6.-H.S. was a man aged 80.

History.-He was admitted complaining of vague upper abdominal pain, constipation, anorexia of three months' duration. Examination revealed a jaundiced and wasted elderly man whose liver was enlarged to three fingerbreadths below the costal margin. Liver function tests suggested biliary obstruction, the serum bilirubin being $9.4 \mathrm{mg} \%$ and alkaline phosphatase 94 units.

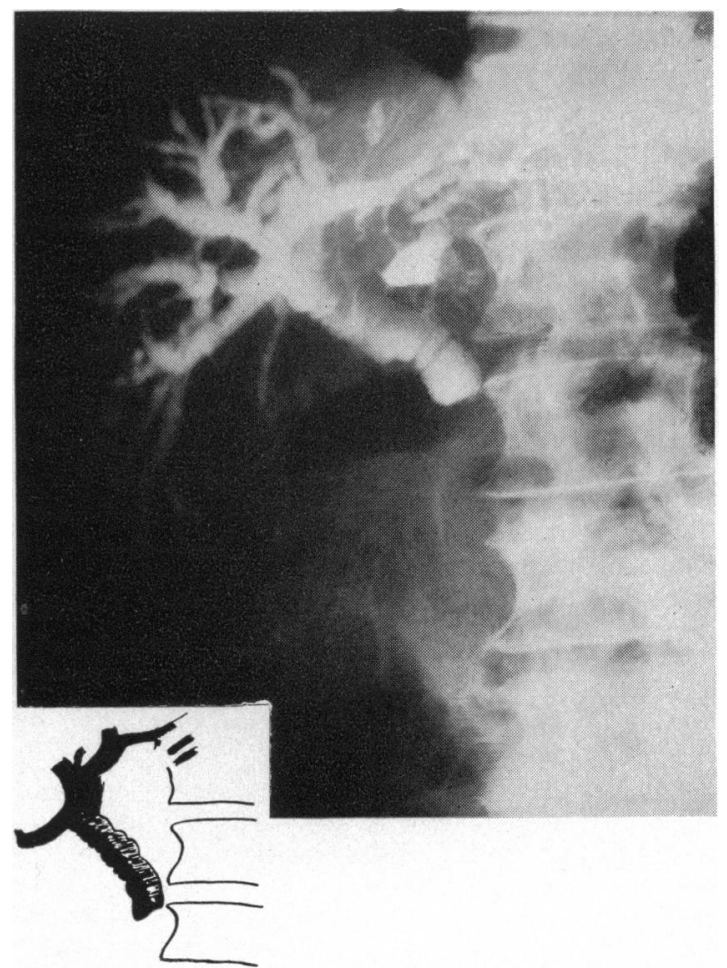

FIG. 6.-Radiograph showing dilatation of the biliary tree. The common bile duct has a crenated outline which was not seen on all films, suggesting that it was due to muscular contraction. 
FIG. 7.-Film taken after barium had been given by mouth to outline the stomach and duodenum. It demonstrates the extent of the obstructive lesion in the lower part of the common duct.

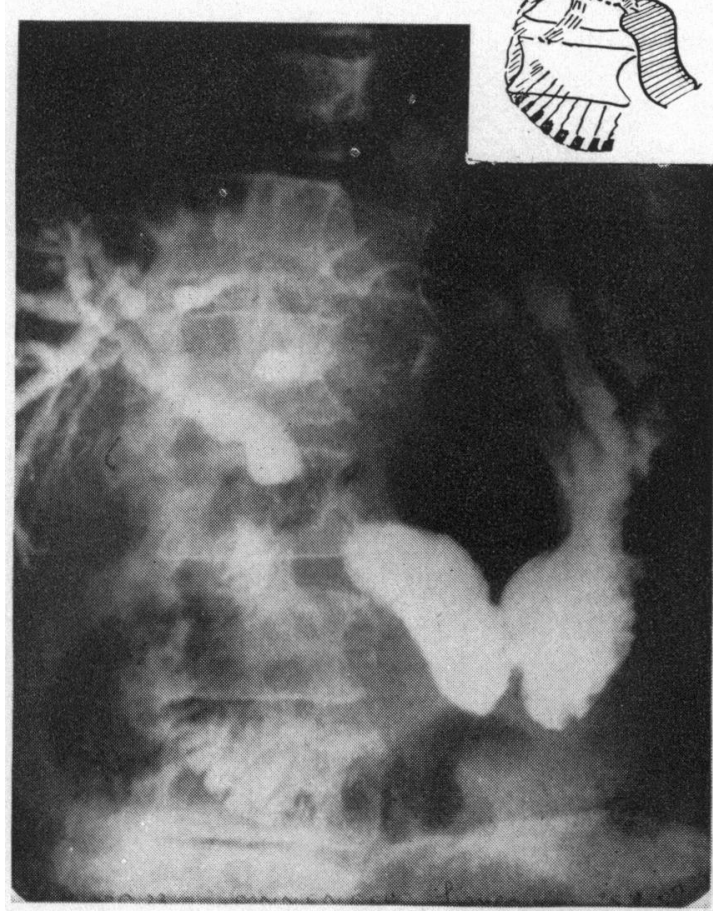

Transhepatic Cholangiography.-Biliary puncture was easily accomplished and after aspiration of golden bile $20 \mathrm{ml}$. of "hypaque" was injected. The intrahepatic biliary tree and upper part of the common duct appeared dilated, the latter having a rather crenated outline (Fig. 6).

Barium suspension was later given by mouth to outline the stomach and duodenum (Fig. 7) where it will be seen that the block extends well up the common duct. A diagnosis of carcinoma of the pancreas was made.

Subsequent laparatomy confirmed this diagnosis and a palliative cholecyst-gastrostomy was performed.

CASE 17.-N.J. was a woman aged 52.

History.-She was admitted complaining of severe attacks of upper abdominal pain and vomiting over a period of 15 months. Three days before admission she had complained of a further attack of severe upper abdominal pain during which she had become jaundiced. No physical signs were present other than the jaundice and a palpable liver two fingerbreadths below the costal margin. Biochemical investigations confirmed the diagnosis of obstructive jaundice, the serum bilirubin being $3.4 \mathrm{mg} . \%$, and the alkaline phosphatase 60 units. Liver biopsy showed numerous bile thrombi and pro- liferating bile ducts in the portal tracts together with inflammatory cells and some increase in fibrous tissue.

Transhepatic Cholangiography.-This was attempted on two occasions, four and five weeks after the onset of jaundice. On neither occasion could a bile passage be punctured.

Laparotomy subsequently revealed no evidence of extrahepatic obstruction, the common bile duct being normal in size and patent. A diagnosis of primary biliary cirrhosis was made.

\section{COMPlications}

In patients in whom cholangiography was impossible no complications occurred. Of those in whom cholangiography was successful the condition of two patients, both suffering from carcinoma

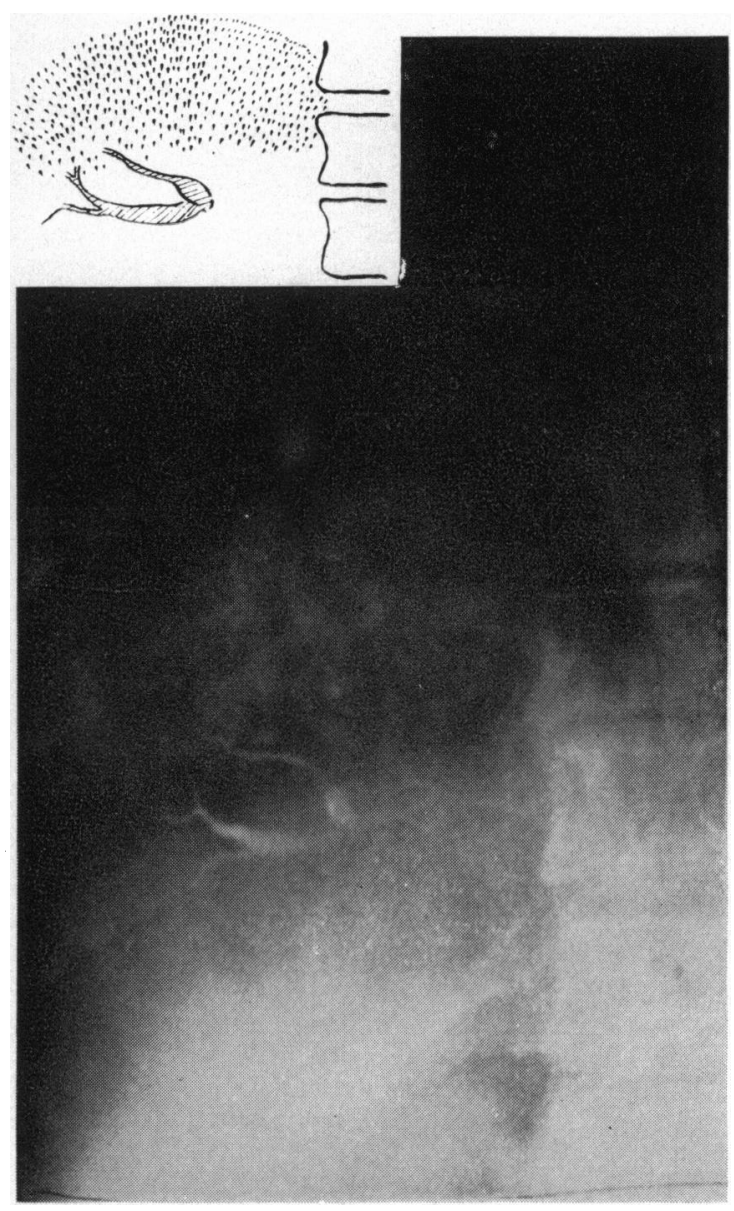

FIG. 8.-Radiograph showing a collection of dilated ducts in the right lobe of the liver associated with extravasation of the dye into the hepatic parenchyma. No ducts were outlined in the left lobe. Diagnosis: carcinoma of the bile ducts at the porta hepatis. 
of the pancreas, gave concern. In the first of these, upper abdominal pain associated with vomiting, was present for 24 hours after the procedure and then subsided spontaneously. Subsequent laparotomy revealed no evidence of a previous biliary leakage. In the second patient, after an interval of some 60 hours, during which an apparently normal recovery took place, the patient complained of severe lower abdominal pain. On examination lower abdominal rigidity suggested a diagnosis of biliary peritonitis. Immediate laparotomy revealed the four puncture sites on the anterior surface of the liver; from one of these, a small laceration rather than a circumscribed puncture wound, bile was seen escaping. A palliative cholecyst-gastrostomy was performed and the right suprahepatic space drained. The patient made an uninterrupted recovery from this complication.

\section{Discussion}

Two important factors must be considered in the evaluation of any diagnostic procedure. First, its safety in relation to other methods of investigation available and secondly the potential usefulness of the method in increasing the accuracy of diagnosis.

Since a procedure which is excessively dangerous cannot justifiably be used this factor requires primary consideration. In most of the reported series attention has been drawn by the authors to the main hazard of transhepatic cholangiography, namely biliary peritonitis. Indeed Richieri (1957), who found an incidence of biliary peritonitis of $30 \%$ and a mortality of $16 \%$ following this procedure, maintained that its use could not be justified. On the other hand, Meeroff (1957) reviewing more than 220 percutaneous transhepatic cholangiographic studies performed at other Argentinian clinics, records no fatality and states that biliary peritonitis ensued in only two.

Review of the literature lends support to Meeroff's view that transhepatic cholangiography is a reasonably safe technique. In addition to Richieri's 36 patients we have traced 277 cases, in 224 of which a cholangiogram was obtained (Table II). In nine of these patients biliary leakage was suspected. In two of these (Wilks, Valenzuela, and Schaposnik, 1958) the cause of this complication was ascribed to accidental puncture of the gall-bladder but in the remaining five patients leakage appears to have been from the liver itself. All except the patients reported by Leger, Zara, and Wargnier (1953) and by Nurick, Patey, and Whiteside (1953) recovered either spontaneously or after laparotomy. This procedure, therefore, carries a potential hazard which may terminate fatally. With careful technique the incidence of biliary peritonitis is of the order of $3.5 \%$, which, however, should be weighed against the equal or greater hazard of "exploratory" laparotomy in the severely jaundiced patient.

It must be emphasized that careful control of respiration during the period when the needle is in the liver is of the utmost importance in avoiding hepatic damage and so reducing the likelihood of

TABLE II

RESULTS IN THE LITERATURE

\begin{tabular}{|c|c|c|c|c|c|}
\hline & & $\begin{array}{l}\text { No. of } \\
\text { Patients }\end{array}$ & $\begin{array}{c}\text { Cholangiogram } \\
\text { Obtained }\end{array}$ & $\begin{array}{c}\text { Biliary Leak } \\
\text { After } \\
\text { Cholangiography }\end{array}$ & $\begin{array}{l}\text { Deaths } \\
\text { Attributed to } \\
\text { Procedure }\end{array}$ \\
\hline $\begin{array}{l}\text { Huard and Do-Xuan-Hop } \\
\text { Carter and Saypol } \\
\text { Leger et al. } \\
\text { Alvarez and Jensen } \\
\text { Crismer } \\
\text { Goni Moreno } \\
\text { Leger et al. } \\
\text { Michelini } \\
\text { Nurick et al. } \\
\text { Fuente et al. } \\
\text { Royer et al. } \\
\text { Sobredo and Garcia Siguero } \\
\text { Kidd } \\
\text { Mandl } \\
\text { Remolar et al. } \\
\text { Royer et al. } \\
\text { Housset and Vantsis } \\
\text { Redington et al. } \\
\text { Felci } \\
\text { Wilks et al. } \\
\text { Barbier } \\
\text { Marcasoli and Cetrá } \\
\text { Kaplan et al. } \\
\text { Present Series }\end{array}$ & $\begin{array}{l}(1937) \\
(1952) \\
(1952) \\
(1953) \\
(1953) \\
(1953) \\
(1953) \\
(1953) \\
(1953) \\
(1954) \\
(1954) \\
(1954) \\
(1956) \\
(1956) \\
(1956) \\
(1956) \\
(1957) \\
(1957) \\
(1958) \\
(1958) \\
(1959) \\
(1959) \\
(1960) \\
(1960)\end{array}$ & $\begin{array}{r}2 \\
1 \\
2 \\
12 \\
6 \\
1 \\
14 \\
1 \\
5 \\
4 \\
6 \\
20 \\
6 \\
25 \\
34 \\
19 \\
9 \\
14 \\
21 \\
41 \\
4 \\
1 \\
8 \\
21\end{array}$ & $\begin{array}{r}2 \\
1 \\
2 \\
9 \\
6 \\
1 \\
14 \\
1 \\
5 \\
4 \\
6 \\
17 \\
6 \\
15 \\
20 \\
15 \\
9 \\
13 \\
19 \\
38 \\
4 \\
1 \\
6 \\
10\end{array}$ & $\begin{array}{l}0 \\
0 \\
0 \\
0 \\
0 \\
0 \\
1 \\
0 \\
1 \\
0 \\
0 \\
0 \\
0 \\
0 \\
0 \\
0 \\
0 \\
2 \\
1 \\
2 \\
0 \\
0 \\
0 \\
2\end{array}$ & $\begin{array}{l}0 \\
0 \\
0 \\
0 \\
0 \\
0 \\
1 \\
0 \\
1 \\
0 \\
0 \\
0 \\
0 \\
0 \\
0 \\
0 \\
0 \\
0 \\
0 \\
0 \\
0 \\
0 \\
0 \\
0\end{array}$ \\
\hline Richieri $^{\text {Total }}$ & (1957) & $\begin{array}{r}277 \\
36\end{array}$ & 224 & $\begin{array}{r}9 \\
11\end{array}$ & $\begin{array}{l}2 \\
6\end{array}$ \\
\hline
\end{tabular}


biliary peritonitis or haemorrhage following percutaneous transhepatic cholangiography. Varela Fuentes, Bertoni, and Polero (1957) go to the length of anaesthetizing the right phrenic nerve to reduce respiratory movement of the liver before performing percutaneous transhepatic cholangiography. Housset and Vantsis (1957) advocate an intercostal approach in the mid-axillary line because they consider that this reduces the risk of these complications. However, it would seem that the chance of entering a large bile duct might be greater using an anterior approach and we therefore prefer this route as greater importance can be attached to a negative examination. Preliminary aspiration before the injection of the contrast medium diminishes the degree of distension of the biliary passages and may thus help to prevent leakage of bile. Percutaneous transhepatic cholangiography should be confined to patients who have been admitted to the ward. Moreover, the examination should only be made in patients in whom operation has been considered and can be undertaken if necessary without delay. Bile leakage is much commoner in patients with extrahepatic biliary obstruction who would in any case presumably require laparotomy.

From Table II it will be observed that this procedure was of positive value in the diagnosis of the cause of jaundice in $80 \%$ of patients. However, in our series the biliary tree was successfully injected in only 11 patients out of 21 . This discrepancy between many previous series and our own is probably due to the fact that we investigated all patients suffering from jaundice with obstructive features by this method. Many of these patients were eventually found to be suffering from intrahepatic biliary obstruction without dilatation of the bile passages. The normal biliary tree is almost impossible to find by needling the liver and hence negative results would be expected in this group. Nurick et al. (1953) and Housset and Vantsis (1957) emphasize that the technique is impracticable in the absence of extrahepatic biliary obstruction. However, in the light of our experience, a negative examination would appear to be of as much diagnostic significance as a successful one. The biliary passages were entered and cholangiography was performed successfully in each of the patients subsequently found to be suffering from extrahepatic obstruction, whereas in none of those later found to have intrahepatic obstruction could bile be aspirated from the liver. We therefore believe that, if jaundice has been present for at least a month, failure to penetrate a bile passage after adequate needling of the liver virtually excludes extrahepatic biliary obstruction. The technique is of special value in the diagnosis of primary biliary cirrhosis which hitherto could only be distinguished from extrahepatic biliary obstruction with certainty by laparotomy and operative cholangiography. Percutaneous transhepatic cholangiography may enable operation to be avoided in these patients.

Dilatation of the biliary tree in extrahepatic biliary obstruction takes time to occur and we would agree with Remolar et al. (1956) that enlargement of the biliary tree is dependent more upon the duration than on the severity of biliary obstruction, hence the proviso that jaundice must have been present for at least one month before significance can be attached to a negative examination.

Percutaneous transhepatic cholangiography is useful in determining the site and cause of extrahepatic obstruction before operation, and in this respect the value of serial films in the diagnosis of biliary calculi must be stressed. The absence of any characteristic deformity of the lower end of the common duct of the rat tail variety, as produced by intrinsic neoplasms elsewhere in the alimentary tract, was rather surprising. This, however, did not detract from the practical value of the method in the diagnosis of carcinoma of the pancreas as a cause of obstructive jaundice. Unfortunately, as might have been expected, cholangiography has not helped to establish the resectability of neoplastic lesions involving the biliary passages.

\section{SUMMARY}

Percutaneous transhepatic cholangiography has been attempted in 21 patients suffering from obstructive jaundice of uncertain origin and the results correlated with the findings at subsequent laparotomy.

Cholangiograms were obtained in each of 11 patients later found to be suffering from extrahepatic obstruction and enabled the correct diagnosis to be made in 10 of these. In contrast, the bile passages could not be entered in any of the remaining 10 patients, each of whom was subsequently discovered to have intrahepatic biliary obstruction, nor was transhepatic cholangiography successful in one additional patient suffering from abdominal pain without jaundice following cholecystectomy.

In addition to its use in indicating the site and nature of extrahepatic obstructive lesions of the bile passages, the technique appears to offer a reliable means of differentiating between intra- and extrahepatic obstruction and is of value in the diagnosis of primary biliary cirrhosis.

One patient required laparotomy for biliary leakage from the puncture wound in the liver. Review of the literature indicates that the incidence of this complication is not greater than $5 \%$. 
We wish to express our thanks to the consultant physicians and surgeons of the General Infirmary at Leeds and St. James's Hospital who have kindly referred their patients to us. We are also indebted to Professor A. S. Johnstone for facilities which his department offered and to Dr. M. Tomlinson for his cooperation. We also wish to thank Mr. A. L. Pegg for the illustrations.

\section{REFERENCES}

Alvarez, R., and Jensen, N. F. (1953). Colangiografia transabdominal. Pren. méd. argent., 40, 1991-1996.

Barbier, F. (1959). De transhepatische Cholangiografie. Belg. T. Geneesk., 15, 1019-1027.

Carter, R. F., and Saypol, G. M. (1952). Transabdominal cholangiography. J. Amer. med. Ass., 148, 253-255.

Crismer, R. (1953). Cholangiographie transcutaneo-hépatique. Acta Gastro-ent. belg., 16, 762-770.

Felci, U. (1958). Colangiografia transèpatica percutanea. Minerva med. (Torino), [Parte Sci.], 49, 130-136.

Fuente, R. de la, Patillo, C., Koch, W., and Mallet-Guy, P. (1954). Exploration des voies biliares au moyen de la cholangiographie trans-abdominale. Lyon chir., 49, 957-962.

Goni Moreno, I. (1953). Colangiografia por poncion percutanea; odditis papilotomia. Bol. Acad. argent. Cirug., 37, 335-337.

Housset, E., and Vantsis, G. (1957). La cholangiographie transpariéto-hépatique. Presse méd., 65, 772-773.

Huard, P., and Do-Xuan-Hop (1937). La ponction transhépatique des canaux biliaires. Bull. Soc. méd.-chir. Indoch., 15, 1090-1100.

Kapandji, M. (1950). Technique de la ponction transpariétohépatique de la vésicule biliaire et radiomanométrie transhépatique désiculaire présopératoire et Rev. Chir. (Paris), 88. hepato-vessiculaire preoperatoire. Rev.

Kaplan, A. A., Brodsky, L., and Rumball, J. M. (1960). Percutaneous transhepatic cholangiography. Amer. J. dig. Dis., 5 (n.s.), 450-457.
Kidd, H. A. (1956). Percutaneous transhepatic cholangiography. A.M.A. Arch. Surg., 72, 262-268.

Leger, L., Zara, M., and Arvay (1952). Cholangiographie et drainage biliaire par ponction trans-hépatique. Presse méd., 60, 936-937.

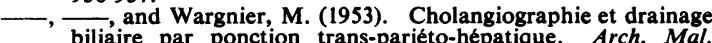
Appar par ponction tian

Mandl, F. (1956). Die transcutane Cholangiographie bei ikterischen Patienten. Chirurg., 27, 341-343.

Marcasoli, A., and Cetra, A. (1959). La colangiografia transparietohepatica en una obesa con hernia umbilical. Sem. parietohepatica en una obesa
méd. (B. Aires), $115,553-556$.

Meeroff, M. (1957). Es la colangiografia transparietohepatica una tecnica diagnostica "inadmisible?". Pren. méd. argent. 44, 3787-3791.

Michelini, R. T. (1953). Colangiografia transabdominal. Ibid., 40, $1094-1096$

Nurick, A. W. Patey D. H and Whiteside, C. G. (1953). Percutaneous transhepatic cholangiography in the diagnosis of obstructive jaundice. Brit. J. Surg., 41, 27-30.

Redington, J. C., Fitzgerald, W. T., and Knight, W. A., Jr. (1957) Percutaneous transhepatic cholangiography. Gastroenterology 33, 273.

Remolar, J., Katz, S., Rybak, B., and Pellizari, O. (1956). Percutaneous transhepatic cholangiography. Ibid., 31, 39-46.

Richieri A. (1957). Editorial. Pren. méd. argent., 44, 2865.

Royer, M., Biempica, L., and Sileoni, V. (1954). La colangiografia laparoscopica transhepatica. Ibid., 41, 1058-1062. Mazure, P. A., Patrizzi, E., and D'Alotto, V. (1956). La cholangiographie transpariéto-hépatique sous controle radioscopique. Presse méd., 64, 976-977.

- and Solari, A. V. (1947). Cholangiography performed with the help of peritoneoscopy. Gastroenterology, 8, 586-591.

Sobredo, E. E., and Garcia Siguero, P. R. (1954). Colangiografia transabdominal. Orientación méd., 3, 1585-1588.

Varela Fuentes, B., Bertoni, C., and Polero, J. (1957). La colangiografia por puncion hepatica. Pren. méd. argent., 44, 2873-2883.

Wilks, A. E., Valenzuela, D., and Schaposnik, F. (1958). Colangiografia transparietohepatica. Ibid,, 45, 2277-2279. 